\title{
Time courses of improvement and symptom remission in children treated with atomoxetine for attention-deficit/hyperactivity disorder: analysis of Canadian open-label studies
}

Ruth A Dickson ${ }^{1 *}$, Ellen Maki ${ }^{2}$, Christopher Gibbins ${ }^{3}$, Stephen W Gutkin ${ }^{4}$, Atilla Turgay ${ }^{5}$ and Margaret D Weiss ${ }^{3}$

\begin{abstract}
Background: The relatively short durations of the initial pivotal randomized placebo-controlled trials involving atomoxetine $\mathrm{HCl}$ for the treatment of attention-deficit/hyperactivity disorder (ADHD) provided limited insight into the time courses of ADHD core symptom responses to this nonstimulant, selective norepinephrine reuptake inhibitor. The aim of this analysis was to evaluate time courses of treatment responses or remission, as assessed by attainment of prespecified scores on the ADHD Rating Scale-IV-Parent Version: Investigator Administered and Scored (ADHDRS-IV-PI) and the Clinical Global Impressions-ADHD-Severity (CGI-ADHD-S) scales, during up to 1 year of atomoxetine treatment in children with ADHD.

Methods: Using pooled data from three Canadian open-label studies involving 338 children ages 6-11 years with ADHD who were treated with atomoxetine for 3, 6 and 12 months, and survival analysis methods for intervalcensored data, we estimated the time to: 1) improvement and robust improvement defined by $\geq 25 \%$ and $\geq 40 \%$ reductions from baseline ADHDRS-IV-PI total scores, respectively; and 2) remission using two definitions: a final score of ADHDRS-IV-PI $\leq 18$ or a final score of CGI-ADHD-S $\leq 2$.
\end{abstract}

Results: The median time to improvement was 3.7 weeks ( 1 month), but remission of symptoms did not occur until a median of 14.3 weeks ( 3.5 months) using the most stringent CGI-ADHD-S threshold. Probabilities of robust improvement were $47 \%$ at or before 4 weeks of treatment; $76 \%$ at 12 weeks; $85 \%$ at 26 weeks; and $96 \%$ at 52 weeks. Probabilities of remission at these corresponding time points were $30 \%, 59 \%, 77 \%$, and $85 \%$ (using the ADHDRS-IV scale) and 8\%, 47\%, 67\%, and 75\% (using the CGI-ADHD-S scale). The change from atomoxetine treatment month 5 to month 12 of -1.01 (1.03) was not statistically significant ( $p=.33$ ).

Conclusions: Reductions in core ADHD symptoms during atomoxetine treatment are gradual. Although approximately one-half of study participants showed improvement at 1 month of atomoxetine treatment, remission criteria were not met until about 3 months. Understanding the time course of children's responses to atomoxetine treatment may inform clinical decision making and also influence the durations of trials comparing the effects of this medication with other ADHD treatments.

Trial Registrations: clinicaltrials.gov: NCT00191633, NCT00216918, NCT00191880.

Keywords: Attention-deficit/hyperactivity disorder atomoxetine, drug therapy, remission, response, treatment outcomes

\footnotetext{
* Correspondence: dickson_ruth@lilly.com

'Eli Lilly Canada, Toronto, Canada and University of Calgary, Alberta, Canada

Full list of author information is available at the end of the article
} 


\section{Background}

Both psychostimulants and the selective norepinephrine reuptake inhibitor atomoxetine $\mathrm{HCl}$ are recommended psychopharmacological treatment options for children diagnosed with attention-deficit/hyperactivity disorder (ADHD), which is considered to be the most common neurobehavioral disorder affecting children [1-3]. In clinical practice, the onset of efficacy and times to symptom improvement and remission during atomoxetine treatment are different from those of stimulant medications, leading to questions about the time required to optimize atomoxetine treatment responses.

Our initial understanding of the time courses of atomoxetine responses was based on randomized placebocontrolled clinical trials with relatively short durations (typically $\leq 9$ weeks) [4-8]. Notably, in these pivotal trials symptom scores appeared to be still descending (improving) at study completion. Hence, it was not possible to determine conclusively from these trials if ADHD core symptoms could continue to decrease, and if so, how quickly (or slowly) and to what extent. These issues have implications for the evolving discussion about ADHD symptom remission as a treatment goal; that is, the concept that the target of ADHD treatment should be minimal or no symptoms, a loss of diagnostic status, and optimal functioning $[9,10]$.

Although attainment of predefined thresholds on validated scales as a measure of symptom remission is a useful barometer of improvement, the time courses of responses to various treatments must be considered when this outcome measure is used to compare interventions; this may be of marked importance when comparing treatments for ADHD-both pharmacological and non-pharmacological (e.g. behavioral and psychoeducational interventions)-that have slower onsets of actions compared with stimulants. Stimulants are notable within the psychopharmacological armamentarium for the relative short time to peak clinical effects.

Improvements in ADHD symptoms have been defined as $\geq 25 \%$ reductions (and robust improvement as $\geq 40 \%$ reductions) on the ADHD Rating Scale-IV-Parent Version: Investigator Administered and Scored (ADHDRSIV-PI) total score [4-11]. However, response definitions based on percentage reduction in scale scores do not take into account baseline symptom severity; for children with very severe disease, robust changes may represent substantial improvements yet leave them very impaired, whereas children with less severe disease who just meet diagnostic criteria may attain normalization for age and gender after only modest percentage reductions in core symptoms. It is therefore helpful for interpreting symptomatic outcomes also to define symptomatic remission. Operational definitions of symptomatic remission include: 1) an ADHDRS-IV-PI total score of $\leq 18$ (average per-item score of $\leq 1$ ), where 0 signifies "not [no symptoms] at all" and 3, "very much"; and 2) a Clinical Global Impressions-ADHD-Severity (CGI-ADHD-S) scale score of $\leq 2$, where 1 signifies "not at all ill," 2 "minimally ill," and 7 "maximal, profound impairment" [4-12].

The primary objective of this study was to determine times to response and remission according to predefined thresholds on the ADHDRS-IV-PI and CGI-ADHD-S scales in children treated with atomoxetine at usual clinical dosages $[11,12]$. To accomplish this aim, we estimated the likelihood of response or remission with atomoxetine as a function of time using pooled data from three Canadian clinical trials with durations of up to 1 year [13-15]. Equipped with a more detailed and nuanced understanding of the time course of treatment responses and remission with atomoxetine, clinicians may be better able to: 1 ) educate (and calibrate the expectations of) children and their parents/guardians/ teachers concerning time courses to different levels of response or remission; 2) decide how long to continue a medication trial; and/or 3) determine if (and when) treatment augmentation or alteration might be needed. By understanding the time courses of response and remission, ADHD researchers may also be better positioned to design more clinically meaningful trials comparing the effects of atomoxetine, stimulants, and/or other treatments.

\section{Methods}

\section{Overview of studies analyzed}

In this retrospective efficacy analysis, data were pooled from three Canadian open-label studies [13-15]. These trials assessed the effects of atomoxetine on both core symptoms and a broad range of other outcome measures (the latter are not considered in this report). The duration of treatment was 3 months in Study S012, 6 months in Study S013, and 1 year in Study LYCS.

\section{Study Participants}

Outpatient boys and girls aged 6 to 11 years $(\mathrm{n}=212$ in Study S012; n = 21 in Study S013; n = 105 in Study LYCS) who had a diagnosis of ADHD according to the Diagnostic and Statistical Manual of Mental Disorders Text Revision (DSM-IV-TR) [16] were eligible. Minimum symptom severity, as measured by the ADHDRSIV-PI total score, was $\geq 1.5$ standard deviations $(S D)$ above age and gender norms. A slight difference between trials was in study participant age ranges at entry: 6 to 11 years in Study S012, 6 to 10 years in Study S013, and 8 to 11 years in Study LYCS. All children had normal intelligence based on investigator judgment and a score of $\geq 85$ if formal IQ testing was conducted. 
Exclusion criteria included a history of bipolar disorder, psychosis, pervasive developmental disorders, conduct disorder, seizure disorder (other than febrile seizures), or serious suicide risk. Eligible study participants also were not using other psychotropic medications and had no medical condition that would contraindicate the use of atomoxetine.

\section{Study designs}

Study participant data were collected at child outpatient clinics in Canada from August 2004 through June 2006. Investigators were child psychiatrists or pediatricians. All studies conformed to ethical principles of the Declaration of Helsinki and all applicable laws, regulations, and good clinical practices, and were approved by ethics committees. Written informed consent was obtained from parents/legal guardians and assent from children. All eligible study participants completed baseline assessments.

In Study LYCS, which commenced before atomoxetine had been approved by Health Canada, atomoxetine treatment was started at $0.5 \mathrm{mg} / \mathrm{kg} /$ day for the first 7 days, then increased to approximately $1.2 \mathrm{mg} / \mathrm{kg} /$ day. An additional increase to the maximum of $1.4 \mathrm{mg} / \mathrm{kg} /$ day or 100 $\mathrm{mg} /$ day (whichever was less) based on efficacy and tolerability profiles was allowed [13]. In Studies S012 and S013 [14,15], atomoxetine was titrated more slowly (according to the approved Canadian atomoxetine product monograph), to a maximum of $1.4 \mathrm{mg} / \mathrm{kg} /$ day as follows: $0.5 \mathrm{mg} / \mathrm{kg} /$ day for the first 10 days; $0.8 \mathrm{mg} / \mathrm{kg} /$ day over the next 10 days; and $1.2 \mathrm{mg} / \mathrm{kg} /$ day for a minimum of 10 days, with an increase to $1.4 \mathrm{mg} / \mathrm{kg} /$ day allowed thereafter. All study participants were atomoxetine-naïve at study entry. Studies also differed in study participants' prior use of stimulants for ADHD. In Study LYCS, all children entering were required to be stimulant-naïve, whereas both stimulant-naïve and stimulant-treated children were eligible for Study SO12 and Study SO13. Use of psychotropic medications other than atomoxetine was not permitted in any of the studies.

\section{Measures}

Efficacy measures in the present study were the ADHDRS-IV-PI and the CGI-ADHD-S [11,12]. The timing of assessments varied across the studies. The ADHDRS-IV-PI was assessed at baseline in all three studies and at: 1) months 1, 3, 5, 8, and 12 in Study LYCS; 2) months 1, 2, and 3 in Study S012; and 3) months 2 and 6 in Study S013. In all three studies, the CGIADHD-S was assessed at baseline and again at week 2 with further assessments at: 1) months 1, 2, 3, 4, 5, 6, 8, 10, 12 in Study LYCS; 2) week 3 and months 1, 2, and 3 in Study S012; and 3) week 3 and months 1, 2, 4, and 6 in Study S013.
Symptom improvement was operationally defined $a$ priori as a $\geq 25 \%$ decrease from baseline on the ADHDRS-IV-PI, and robust improvement as a $\geq 40 \%$ decrease. Remission was defined in two ways: by a threshold ADHDRS-IV-PI score $\leq 18$ or a CGI-ADHD-S score $\leq 2$.

\section{Statistical Analyses}

Responses noted for the first time at a given visit are unlikely to have occurred precisely at the moment of the assessment; we can most accurately state that the response occurred at some time between the current and the most recent previous visit. In such cases, the data are said to be "interval-censored" [17]. Some study participants had not achieved a response by the time of their final assessment; therefore, the time between baseline and their last assessment served as a lower bound on the time required to attain a response. Such data are said to be "right-censored" [18]. Our pooled dataset contained both interval- and right-censored data.

Survival analysis techniques, which utilize data from all study participants to the point that they either experience a response or are no longer available to be followed, are the most appropriate methods for handling censored data where the endpoint is the time to an event of interest. Such methods allow data contributed by study participants who withdrew early, or completed the study but did not respond, to be included in the analysis. These methods could accommodate data from all three studies, regardless of the fact that the assessment times varied between studies, and could also allow inclusion of data from unscheduled visits and visits that occurred outside of prescribed visit windows.

Because the time necessary to realize each of the four treatment response criteria was of interest in the current investigation, survival analysis methods were used. Turnbull's extension of the Kaplan-Meier curve to interval-censored data was used to estimate the cumulative probability of response over time (survivor function) as well as to estimate the median time to response [17]. A log-normal parametric model was used to assess the univariate impact of baseline ADHDRS-IV-PI and baseline CGI-ADHD-S on the time to each of the four endpoints of interest. A repeated-measures linear mixed model was used to obtain the least-squares mean of ADHDRS-IV-PI by month.

\section{Results}

\section{Baseline characteristics}

The pooled study sample comprised 249 (73.7\%) boys and $89(26.3 \%)$ girls whose mean (standard error $[S E]$ ) age (overall) was $8.7(0.08)$ years. Of study participants in Study S012, 54.7\% were stimulant-naïve compared with $38.1 \%$ of those in Study S013 and 100\% of those in 
Table 1 Summary of Baseline Characteristics

\begin{tabular}{ccccc}
\hline Characteristic & \multicolumn{4}{c}{ Study } \\
\cline { 2 - 5 } & $\begin{array}{c}\text { LYCS } \\
(\mathbf{n}=\mathbf{1 0 5})\end{array}$ & $\begin{array}{c}\text { S012 } \\
\mathbf{( n = 2 1 2 )}\end{array}$ & $\begin{array}{c}\text { S013 } \\
(\mathbf{n}=\mathbf{2 1})\end{array}$ & $\begin{array}{c}\text { All } \\
\text { (N = 338) }\end{array}$ \\
\hline Gender, male, n (\%) & $76(72.4)$ & $157(74.1)$ & $16(76.2)$ & $249(73.7)$ \\
Age & $9.3(0.08)$ & $8.5(0.11)$ & $8.0(0.28)$ & $8.7(0.08)$ \\
ADHD subtype, n (\%) & & & & \\
Combined & $74(70.5)$ & $166(78.3)$ & $6(28.6)$ & $246(72.8)$ \\
Inattentive & $31(29.5)$ & $43(20.3)$ & $15(71.4)$ & $89(26.3)$ \\
Hyperactive/impulsive & $0(0.0)$ & $3(1.4)$ & $0(0.0)$ & $3(0.9)$ \\
Stimulant-naïve, n (\%) & $105(100.0)$ & $116(54.7)$ & $8(38.1)$ & $229(67.8)$ \\
ADHDRS-IV-PI & $37.0(0.84)$ & $40.5(0.52)$ & $35.9(1.13)$ & $39.1(0.43)$ \\
CGI-ADHD-S & $4.6(0.08)$ & $4.8(0.06)$ & $4.9(0.10)$ & $4.8(0.05)$ \\
\hline ADHDRS-IV-PI $=$ Att
\end{tabular}

ADHDRS-IV-PI = Attention-Deficit/Hyperactivity Disorder Rating Scale Parent Version: Investigator Administered and Scored; CGI-ADHD-S = Clinical Global Impression of ADHD Severity.

Mean (SE) or numbers (\%).

Study LYCS. Mean (SE) baseline scores were $39.1(0.43)$ on the ADHDRS-IV-PI and $4.8(0.05)$ on the CGIADHD-S (Table 1).

\section{Subject disposition}

Approximately $70 \%$ of study participants completed each study: $68.6 \%$ in LYCS, $70.8 \%$ in S012, and $76.2 \%$ in S013.

The most common reason for discontinuation in all studies was lack of efficacy as perceived by the child/ caregiver or physician (10.7\%), followed by adverse events $(6.5 \%)$. Five (1.5\%) study participants were lost to follow-up.

\section{Outcomes}

The median number of weeks from baseline to the last available ADHDR-IV-PI assessment for the pooled studies was 13 weeks ( 3 months). The follow-up time between the baseline and last available assessment varied according to the duration of each study. Table 2 reports the mean $(S E)$ and median (range) duration of follow-up (weeks) by individual study, as well as for the combined studies.

Atomoxetine treatment reduced ADHD symptoms sharply during the first month and was associated with further reductions in subsequent months. Mean ADHDRS-IV-PI total scores leveled out at approximately month 5 (Table 3 ). The change from atomoxetine treatment month 5 to month 12 of -1.01 (1.03) was not statistically significant $(p=.33)$.

As shown in Table 4, the median time to treatment response varied markedly by criterion. The median time to improvement according to the least stringent criterion of treatment response was 3.7 weeks; the probability of improvement was estimated at $60 \%$ at or before 4 weeks and $88 \%$ at or before 12 weeks. The median time
Table 2 Summary of Subject Follow-up

\begin{tabular}{ccccc}
\hline & \multicolumn{4}{c}{ Study } \\
\cline { 2 - 5 } & LYCS & S012 & S013 & All \\
\hline Weeks From & Baseline to Last & ADHDRS-IV-PI & Assessment \\
$\mathrm{N} \dagger$ & 102 & 198 & 20 & 320 \\
Mean (SE) & $42.7(1.63)$ & $11.5(0.23)$ & $22.5(1.64)$ & $22.2(0.97)$ \\
Median & 51.3 & 12.9 & 25.9 & 13.3 \\
Range & $3.9-58.0$ & $1.0-17.3$ & $4.4-27.1$ & $1.0-58.0$ \\
Weeks From Baseline to Last & CGI-ADHD-S Assessment \\
N† & 102 & 206 & 21 & 329 \\
Mean (SE) & $43.1(0.15)$ & $11.2(0.25)$ & $21.5(1.9)$ & $21.7(0.96)$ \\
Median & 51.3 & 12.7 & 25.9 & 13.3 \\
Range & $2.3-58.0$ & $1.0-17.3$ & $1.6-27.1$ & $1.0-58.0$ \\
\hline
\end{tabular}

tOnly study participants with both a baseline value and at least one postbaseline value were included in this summary.

ADHDRS-IV-PI = Attention-Deficit/Hyperactivity Disorder Rating Scale Parent Version: Investigator Administered and Scored; CGI-ADHD-S = Clinical Global Impression of ADHD Severity.

to a robust improvement was slightly greater $(4.7$ weeks), whereas the estimated probability of a robust improvement was $47 \%$ at or before week 4 and $76 \%$ at or before week 12 (Table 4).

Longer treatment intervals were required to meet definitions of symptom remission. The median time to remission, defined as a total ADHDRS-IV-PI of $\leq 18$, was 8.0 weeks, and the probability of remission did not reach $75 \%$ until approximately 24 weeks. To meet the most rigorous criterion for remission (achieving a CGIADHD-S score $\leq 2$ ), the median time was 14.3 weeks. For this endpoint, the probability of remission by 26 weeks was approximately $67 \%$ (Table 4 ).

Figure 1 presents the estimated cumulative probability (Turnbull estimate) of meeting the response/remission criteria at or before each month of atomoxetine treatment; the curves for each of the four criteria are shown. For each of the four treatment response criteria, the estimated probability of achieving the endpoint at or before week 16 of atomoxetine treatment was at least $50 \%$, and by week 20 it was at least $60 \%$.

Table 3 ADHDRS-IV-PI Least-Square (LS) Mean by Month of Atomoxetine Treatment

\begin{tabular}{lcc}
\hline Time Point & N & LS Mean (SE) \\
\hline Day 0 & 335 & $39.12(0.43)$ \\
Month 1 & 282 & $22.88(0.65)$ \\
Month 2 & 179 & $21.00(0.67)$ \\
Month 3 & 176 & $19.93(0.67)$ \\
Month 5 & 85 & $17.83(0.85)$ \\
Month 6 & 21 & $17.48(1.79)$ \\
Month 8 & 81 & $17.27(0.92)$ \\
Month 12 & 72 & $16.82(0.99)$ \\
\hline
\end{tabular}

ADHDRS-IV-PI = Attention-Deficit/Hyperactivity Disorder Rating Scale Parent Version: Investigator Administered and Scored. 
Table 4 Response Probabilities Over Time

\begin{tabular}{|c|c|c|c|c|c|c|c|}
\hline \multirow[t]{2}{*}{ Endpoint } & \multicolumn{4}{|c|}{$\begin{array}{l}\text { Probability That Endpoint Was Observed at or } \\
\text { Before: }\end{array}$} & \multicolumn{3}{|c|}{$\begin{array}{l}\text { Expected Week by Which This Percentage of Study Participants } \\
\text { Will Have Achieved Endpoint: }\end{array}$} \\
\hline & 4 weeks & 12 weeks & 26 weeks & 52 weeks & $25 \%$ & $50 \%$ & $75 \%$ \\
\hline Improvement & $\begin{array}{c}0.60 \\
(0.38,0.79)\end{array}$ & $\begin{array}{c}0.88 \\
(0.75,0.95)\end{array}$ & $\begin{array}{c}0.96 \\
(0.85,0.99)\end{array}$ & 1.00 & - & 3.7 & 7.2 \\
\hline Robust Improvement & $\begin{array}{c}0.47 \\
(0.30,0.65)\end{array}$ & $\begin{array}{c}0.76 \\
(0.60,0.87)\end{array}$ & $\begin{array}{c}0.85 \\
(0.67,0.94)\end{array}$ & $\begin{array}{c}0.96 \\
(0.87,0.99)\end{array}$ & 3.6 & 4.7 & 12.0 \\
\hline Remission* & $\begin{array}{c}0.30 \\
(0.16,0.49)\end{array}$ & $\begin{array}{c}0.59 \\
(0.34,0.79)\end{array}$ & $\begin{array}{c}0.77 \\
(0.48,0.92)\end{array}$ & $\begin{array}{c}0.85 \\
(0.72,0.93)\end{array}$ & 3.7 & 8.0 & 23.8 \\
\hline Remission** & $\begin{array}{c}0.08 \\
(0.04,0.16)\end{array}$ & $\begin{array}{c}0.47 \\
(0.26,0.70)\end{array}$ & $\begin{array}{c}0.67 \\
(0.51,0.80)\end{array}$ & $\begin{array}{c}0.75 \\
(0.60,0.85)\end{array}$ & 5.3 & 14.3 & 52.3 \\
\hline
\end{tabular}

${ }^{\dagger}$ Probability with $95 \%$ confidence interval.

Remission using two definitions: *final score of ADHDRS-IV-PI $\leq 18$, and ${ }^{* *}$ CGI-ADHD-S $\leq 2$. ADHDRS-IV-PI = Attention-Deficit/Hyperactivity Disorder Rating Scale Parent Version: Investigator Administered and Scored; CGI-ADHD-S = Clinical Global Impression of ADHD Severity.

On univariate analysis, the baseline value of ADHDRS-IV-PI total score was a significant predictor of the time to improvement, robust improvement, and an ADHDRS-IV-PI $\leq 18$, but not of a CGI-ADHD-S score of $\leq 2$. Higher baseline ADHDRS-IV-PI scores (indicative of more severe ADHD symptomatology) were associated with a shorter time to improvement and robust improvement; whereas lower baseline ADHDRS-IV-PI total scores were associated with a shorter time to attain remission. The baseline value of CGI-ADHD-S was also a significant predictor of time to remission, with lower values (indicative of less severe ADHD symptomatology) being associated with shorter time required to achieve remission defined as a CGIADHD-S score of $\leq 2$.

\section{Discussion}

In this study, there was a progressive increase in the likelihood that treatment met predefined thresholds for

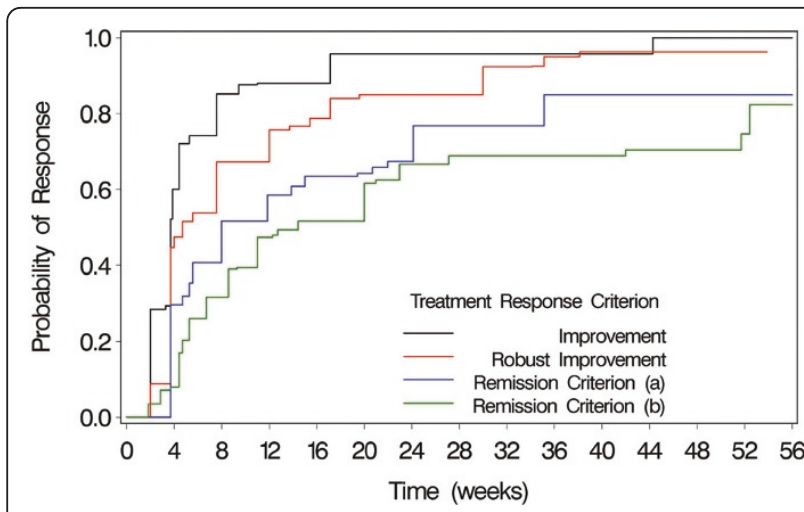

Figure 1 Response Probabilities Over Time. Response using two definitions: improvement $=\geq 25 \%$ reduction from baseline on the ADHDRS-IV-PI and robust improvement $=\geq 40 \%$ reduction. Remission using two definitions: a final score of (a) ADHDRS-IV-PI $\leq 18$ or (b) CGI-ADHD-S $\leq 2$. ADHDRS-IV-PI = ADHD Rating Scale Parent Version: Investigator Administered and Scored; CGI-ADHD-S = Clinical Global Impressions-ADHD-Severity. response and remission with increasing time on atomoxetine. Of interest, children's ADHD symptoms continued to improve up to approximately 5 months. Although there was symptomatic improvement as measured by the ADHDRS-IV-PI total score beyond this time, the change was not statistically significant.

The present analysis of three Canadian open-label clinical trials of atomoxetine produced clinically meaningful findings that are consistent with data from two recently reported European randomized, double-blind, placebo-controlled studies that reported increased efficacy of atomoxetine over time $[19,20]$. First, a Spanish study of 151 treatment-naïve children and adolescents (mean age $=10.3$ years) with newly diagnosed ADHD showed that reductions (improvements) in the ADHDRS-IV-PI total score in the atomoxetine (vs. placebo) group first reached statistical significance at treatment week 4; of importance, statistically significant reductions in ADHD symptoms were evident between weeks 6 and 12 [19]. Similarly, in a 10-week Swedish study involving 99 stimulant-naïve children and adolescents (mean age $=11.5$ years), mean changes in the ADHDRS-IV-PI total score from baseline in study participants receiving atomoxetine in combination with psychoeducation (vs. placebo in combination with psychoeducation) reached statistical significance at treatment week 3 and continued to improve at each subsequent visit [20].

The gradual and progressive efficacy of atomoxetine in treating core symptoms of ADHD, which was observed in the present study, has potential implications for understanding three previously reported studies comparing the effects of atomoxetine to those of long-acting stimulants [21-23]. The Strattera Adderall XR Randomized Trial (St.A.R.T) was an analog classroom study designed to assess the time course of treatment effect, tolerability, and safety of mixed amphetamine salts extended-release (MAS XR) compared with atomoxetine in children with ADHD. The randomized double-blind 
treatment period was 18 days. The authors concluded that the difference in effect size in this study indicated a more robust treatment effect of MAS XR [23]. The open-label study by Kemner and co-workers (2005) concluded that treatment with osmotic-release oral system methylphenidate (OROS MPH) exerted greater effects on core ADHD symptoms compared with atomoxetine; however, this was a short-term study (3 weeks) [22]. A 6-week active-comparator study also found that OROS $\mathrm{MPH}$ was superior to atomoxetine for the total group, but there were no differences in response rates for the treatment-naïve subgroup [21].

Evidence from these comparator studies, the European studies discussed above $[19,20]$, and our analysis supports the clinical perception that atomoxetine is not the ideal treatment for patients who require rapid control of symptoms. However, it is potentially misleading to compare effects of long-acting stimulants to those of atomoxetine based on short-term studies because atomoxetine requires a longer treatment period to: 1 ) attain an initial response and 2) achieve maximal possible reductions in ADHD symptoms. Long-term direct comparison studies of atomoxetine and stimulants are necessary to determine if the patterns of symptom improvement with atomoxetine treatment differ from those with stimulants in the long term as well as the short term.

In our study, baseline illness severity substantially influenced the time to meet predefined measures of improvement. Children initiating atomoxetine therapy with higher symptom severity scores met percentage improvement criteria in a shorter time than children starting with lower baseline symptom severity scores. In contrast, children rated as less severely symptomatic on the CGI-ADHD-S and ADHDRS-IV-PI achieved remission thresholds more rapidly. Of clinical interest, the Integrated Data Exploratory Analysis study, a retrospective analysis of randomized controlled trials having 6- to 9-week durations, did not identify potential baseline (moderator) predictors of response but did find that the only predictor (on-treatment mediator) of a much improved response at trial endpoint $(\geq 40 \%$ decrease on the ADHDRS-IV-PI) was being at least minimally improved ( $225 \%$ but $<40 \%$ decrease on the ADHDRSIV-PI) by treatment week 4 [24]. This finding of improvement at 4 weeks' predicting later improvement, taken together with the possibility of continued improvement over time (as found in the present Canadian and European studies [13-15,19,20]), suggests that monitoring for improvement at 1 month is valuable, as is continued monthly monitoring to confirm the presence of progressive improvement in ADHD symptoms that would justify continuation of atomoxetine treatment.

\section{Limitations}

Our findings are most generalizable to Canadian children ages 6 to 11.5 years who: 1 ) are of at least average intelligence and whose ADHD symptoms are well above age and gender norms for severity; 2) do not have comorbid conditions such as bipolar disorder, psychoses, pervasive developmental disorders, conduct disorder, or serious suicide risk; and/or 3) are treated with atomoxetine on an outpatient basis. Most study participants $(>70 \%)$ were boys and had the combined subtype of ADHD. In addition, approximately two-thirds of enrolled children (and all participants in the 1-year study) were previously untreated with ADHD medications and therefore may have been more responsive to medication than children who had received, but failed, prior treatments. The trials were all open label, and this study design feature may have encouraged positive clinician bias in estimating improvements; in Canada, it was considered unethical to include a placebo arm in extended-duration studies of ADHD. The results of the three open-label trials included in our study may have been influenced by initial patient selection and rater drift. Given the characteristics of our sample, the designs of the studies, and the potential advantages to children of clinical trial participation, it is possible that the relatively high rates of response we report with atomoxetine treatment will not be replicated in usual clinical practice.

The slow upward titration of atomoxetine and the differences in the titration schedules mandated by the study protocols may have had some impact on early response rates, but it is unlikely that the dosing of atomoxetine during the initial part of the study impacted the major finding of the study, which was that there is slow but progressive improvement over time during atomoxetine treatment long after titration is complete.

Only one of the primary studies (Study SO13) analyzed herein included teachers' evaluations, precluding inclusion of teachers' important perspectives on time courses to response or remission with atomoxetine. In Study S013, baseline symptom ratings completed by the teachers were indicative of less severe symptoms than ratings completed by parents, but the progressive improvements during this 6-month study showed that symptom decrements noted by parents paralleled those of teachers [14]. In addition to including data from a limited range of informants, our analyses were limited to measures of core ADHD symptoms. Achieving a pre-defined 'remission' score on the CGIADHD-S is indicative of improvement in ADHD symptomatology but does not necessarily mean that the child is without impairments. Future clinical trials, especially those comparing different treatments, should evaluate times to achievement of thresholds or norms on other important measures, including health-related quality-of-life and functional/cognitive/neuropsychological outcomes. 
Not all subjects had 12 months of follow-up; the three studies varied in length from 3-12 months and in addition approximately $30 \%$ of children did not complete their study. Therefore, we chose methods of analysis (survival curves) that do not require an equal length of follow-up for each subject and that did not require that all subjects complete the study. These methods estimate response probabilities over time by using the data for each subject up to the point that they either responded or withdrew from the study. We don't know the time by which the drop-outs would have responded but each participant contributes information: for example, a child who discontinued at week 6 prior to responding provides information on the probability of achieving (or not achieving) a response by week 6 .

When interpreting such curves, it is essential to understand both that there are declining numbers of participants over time, and that the cumulative response probability at a given time point is based not only on those subjects still under observation, but also on the pattern of response and withdrawals at all previous time points. Thus the response probability at a certain time depends directly on those still under observation, and indirectly on those who withdrew or responded earlier.

\section{Conclusions}

Our findings concerning time courses of response and remission with atomoxetine may inform future study design and clinical decision making. From a clinical perspective, appropriate expectations should be set with children and parents at the time of atomoxetine initiation, because reductions in symptoms are gradual but appear to progress over time. Designs of future comparison studies of medications to treat ADHD should consider differences in time of onset of efficacy (and time to peak response) between atomoxetine and stimulants and/or other treatments.

\footnotetext{
Abbreviations

ADHD: attention-deficit/hyperactivity disorder; ADHDRS-IV-PI: ADHD Rating Scale Parent Version: Investigator Administered and Scored; CGI-ADHD-S: Clinical Global Impressions-ADHD-Severity; MAS XR: mixed amphetamine salts extended-release; OROS MPH: osmotic-release oral system methylphenidate;
}

\footnotetext{
Acknowledgements

Funding for this research was provided by Eli Lilly Canada, Toronto, which had a role in study design, data acquisition and interpretation, and the decision to publish the findings.

Selected findings were presented at the 56th Annual Meeting of the American Academy of Child and Adolescent Psychiatry, October 27-

November 1, 2009, Hilton Hawaiian Village, Honolulu, Hawaii (Poster \#10292).

\section{Author details}

${ }^{1}$ Eli Lilly Canada, Toronto, Canada and University of Calgary, Alberta, Canada. ${ }^{2}$ Analytica Statistical Consulting, Don Mills, Ontario, Canada. ${ }^{3}$ Children's and
} Women's Health Centre of British Columbia, Mental Health Research Unit,
Vancouver, Canada. ${ }^{4}$ Rete Biomedical Communications Corp., Wyckoff, NJ, USA. ${ }^{5}$ University of Toronto and Toronto ADHD Clinic, Ontario, Canada.

\section{Authors' contributions}

All authors contributed to the conception and design of the study. MDW, AT, and other clinical investigators acquired data. EM conducted the statistical analysis. All authors interpreted the data. RAD, EM and SWG wrote the manuscript, and all authors contributed to the manuscript. All have read and approved the final manuscript except for AT. Dr. Atilla Turgay (deceased) participated in the data analysis and an early draft of the manuscript. RAD had access to all data and takes responsibility for the study and its report (study guarantor).

\section{Competing interests}

RAD: employee of the study sponsor with stock or equity $>\$ 10,000$. EM: paid consultant to the study sponsor. CG: no competing interests to disclose. SWG: paid consultant to the study sponsor and its affiliates, as well as BioBehavioral Diagnostics. MDW: advisory boards and speakers' bureaus, consultant, grant and/or other research support, study sponsor, Abbott, Janssen, Purdue Pharma, Shire, Takeda; speakers' bureau, Novartis; travel support from study sponsor to present poster at congress.

Received: 4 November 2010 Accepted: 11 May 2011

Published: 11 May 2011

\section{References}

1. Canadian ADHD Resource Alliance (CADDRA): Canadian ADHD Practice Guidelines 2011 [http://www.caddra.ca/cms4/], Accessed April 25, 2011.

2. Faraone SV, Sergeant J, Gillberg C, Biederman J: The worldwide prevalence of ADHD: is it an American condition? World Psychiatry 2003, 2:104-113.

3. Pliszka S, AACAP Work Group on Quality Issues: Practice parameter for the assessment and treatment of children and adolescents with attentiondeficit/hyperactivity disorder. J Am Acad Child Adolesc Psychiatry 2007, 46:894-921.

4. Kelsey DK, Sumner CR, Casat CD, Coury DL, Quintana H, Saylor KE, Sutton VK, Gonzales J, Malcolm SK, Schuh KJ, Allen AJ: Once-daily atomoxetine treatment for children with attention-deficit/hyperactivity disorder, including an assessment of evening and morning behavior: a double-blind, placebo-controlled trial. Pediatrics 2004, 114:e1-e8.

5. Michelson D, Faries D, Wernicke J, Kelsey D, Kendrick K, Sallee FR, Spencer T, Atomoxetine ADHD Study Group: Atomoxetine in the treatment of children and adolescents with attention-deficit/ hyperactivity disorder: a randomized, placebo-controlled, dose-response study. Pediatrics 2001, 108:E83.

6. Michelson D, Allen AJ, Busner J, Casat C, Dunn D, Kratochvil C, Newcorn J, Sallee FR, Sangal RB, Saylor K, West S, Kelsey D, Wernicke J, Trapp NJ, Harder D: Once-daily atomoxetine treatment for children and adolescents with attention deficit hyperactivity disorder: a randomized, placebo-controlled study. Am J Psychiatry 2002, 159:1896-1901.

7. Spencer T, Heiligenstein JH, Biederman J, Faries DE, Kratochvil CJ, Conners CK, Potter WZ: Results from 2 proof-of-concept, placebocontrolled studies of atomoxetine in children with attention-deficit/ hyperactivity disorder. J Clin Psychiatry 2002, 63:1140-1147.

8. Weiss M, Tannock R, Kratochvil C, Dunn D, Velez-Borras J, Thomason C, Tamura R, Kelsey D, Stevens L, Allen AJ: A randomized, placebo-controlled study of once-daily atomoxetine in the school setting in children with ADHD. J Am Acad Child Adolesc Psychiatry 2005, 44:647-655.

9. Steele M: Introduction to remission in ADHD: raising the bar. Clin Ther 2006, 28:1879-1881.

10. Steele $M$, Jensen PS, Quinn DM: Remission versus response as the goal of therapy in ADHD: a new standard for the field? Clin Ther 2006, 28:1892-1908.

11. DuPaul $G$, Reid R, Power $T$, Anastopoulos A: ADHD rating scale-IV: checklists, norms, and clinical interpretations. New York, NY: Guilford Publications, Inc; 1998

12. Guy W: ECDEU: assessment manual for psychopharmacology, revised Rockville, MD: US Dept. of Health, Education, and Welfare; 1976.

13. Dickson R, Lee B, Turgay A, Chang S, White H, Davis L, Wasdell M, Yoshioka A, Weiss M: Atomoxetine treatment of ADHD: symptomatic, academic, cognitive, and functional outcomes. Presented at the American 
Academy of Child and Adolescent Psychiatry, 54th Annual Meeting, Boston, MA 2007.

14. Maziade M, Rouleau N, Lee B, Rogers A, Davis L, Dickson R: Atomoxetine and neuropsychological function in children with attention-deficit/ hyperactivity disorder: results of a pilot study. J Child Adolesc Psychopharmacol 2009, 19:709-718.

15. Dickson RA, Jackiewicz G, Khattak S, Gilchrist W, Szombathy S, Brunner E: Change in ADHD symptoms and functional outcomes in Canadian children during 3 months of atomoxetine treatment. Presented at the 27th Annual Conference of the Canadian Academy of Child and Adolescent Psychiatry, Montréal, Québec 2007.

16. American Psychiatric Association (APA): Diagnostic and statistical manual of mental disorders text revision (DSM-IV-TR) Washington, DC: APA; 2000.

17. Turnbull BW: The empirical distribution function with arbitrarily grouped, censored, and truncated data. J Royal Stat Soc Series B 1976, 38:290-295.

18. Lawless J: Statistical Models and Methods for Lifetime Data Hoboken, NJ: John Wiley and Sons; 2003.

19. Montoya A, Hervas A, Cardo E, Artigas J, Mardomingo MJ, Alda JA, Gastaminza X, Garcia-Polavieja MJ, Gilaberte I, Escobar R: Evaluation of atomoxetine for first-line treatment of newly diagnosed, treatment-naive children and adolescents with attention deficit/hyperactivity disorder. Curr Med Res Opin 2009, 25:2745-2754.

20. Svanborg P, Thernlund G, Gustafsson PA, Hagglof B, Poole L, Kadesjo B: Efficacy and safety of atomoxetine as add-on to psychoeducation in the treatment of attention deficit/hyperactivity disorder: a randomized, double-blind, placebo-controlled study in stimulant-naive Swedish children and adolescents. Eur Child Adolesc Psychiatry 2009, 18:240-249.

21. Newcorn JH, Kratochvil CJ, Allen AJ, Casat CD, Ruff DD, Moore RJ, Michelson D, Atomoxetine/Methylphenidate Comparative Study Group: Atomoxetine and osmotically released methylphenidate for the treatment of attention deficit hyperactivity disorder: acute comparison and differential response. Am J Psychiatry 2008, 165:721-730.

22. Kemner JE, Starr HL, Ciccone PE, Hooper-Wood CG, Crockett RS: Outcomes of OROS methylphenidate compared with atomoxetine in children with ADHD: a multicenter, randomized prospective study. Adv Ther 2005, 22:498-512.

23. Wigal SB, McGough JJ, McCracken JT, Biederman J, Spencer TJ, Posner KL, Wigal TL, Kollins SH, Clark TM, Mays DA, Zhang Y, Tulloch SJ: A laboratory school comparison of mixed amphetamine salts extended release (Adderall XR) and atomoxetine (Strattera) in school-aged children with attention deficit/hyperactivity disorder. J Atten Disord 2005, 9:275-289.

24. Newcorn JH, Sutton VK, Weiss MD, Sumner CR: Clinical responses to atomoxetine in attention-deficit/hyperactivity disorder: the Integrated Data Exploratory Analysis (IDEA) study. J Am Acad Child Adolesc Psychiatry 2009, 48:511-518.

doi:10.1186/1753-2000-5-14

Cite this article as: Dickson et al:: Time courses of improvement and symptom remission in children treated with atomoxetine for attentiondeficit/hyperactivity disorder: analysis of Canadian open-label studies.

Child and Adolescent Psychiatry and Mental Health 2011 5:14.

\section{Submit your next manuscript to BioMed Central and take full advantage of:}

- Convenient online submission

- Thorough peer review

- No space constraints or color figure charges

- Immediate publication on acceptance

- Inclusion in PubMed, CAS, Scopus and Google Scholar

- Research which is freely available for redistribution

Submit your manuscript at www.biomedcentral.com/submit
Ciomed Central 